\title{
HALUHALUNEKISU E AS EPISTEMOLOGIAS CONSTITUCIONAIS DO SUL
}

\section{Loyuá Ribeiro Fernandes Moreira da Costa*}

Resumo: O Novo Constitucionalismo Latino-Americano traz um projeto de Estado voltado à descolonialidade proporcionada pelo Buen Vivir. Essa cosmologia, advinda das etnias Kichwa e Aimará, não possui caráter liberal e é adotada pelas constituições da Bolívia e do Equador. Ao desafiar o direito a novas perspectivas para com a Natureza, permite reconhecer e lidar com as consequências da universalização da epistemologia do Norte. A urgência de se interrogar sobre uma epistemologia constitucional del Sul convoca o Direito a reconhece-las e a acolhê-las como seu fundamento. No mesmo sentido, a cosmologia brasileira Nambiquara, Haluhalunekisu, possibilita novas reflexões epistemológicas para um despertar descolonial.

Palavras-chave: Novo Constitucionalismo Latino Americano; Epistemologias do Sul; Direitos da Natureza; Haluhalunekisu; Buen Vivir.

\section{HALUHALUNEKISU AND THE SOUTHERN CONSTITUTIONALISM EPISTEMOLOGIES}

\begin{abstract}
The New Latin American Constitutionalism holds a State project focused on the decoloniality of the Buen Vivir. This Kichwa and Aimará cosmology conceive Nature not in a liberal way and is adopted by Bolivia and Ecuador constitutions. By challenging the Right to new perspectives of Nature, it recognizes and deal with the consequences of the North epistemology universalization. The urgency searching for Southern constitutional epistemologies summons the Right to recognize Southern cosmology. In the same sense, the Brazilian cosmology Nambiquara, Haluhalunekisu, makes possible new epistemological reflections for a decolonial awakening.
\end{abstract}

Keywords: New Latin American Constitutionalism; Epistemologies of the South; Nature rights; Haluhalunekisu; Buen Vivir.

\footnotetext{
* Mestranda em Direito Constitucional pela Universidade Federal Fluminense. Integrante do grupo Inpodderales (Laboratório de Inovação, Pesquisa e Observação em Direito, Democracia e Representações da América Latina e Eixo Sul), na Faculdade Nacional de Direito da Universidade Federal do Rio de Janeiro. E-mail: lrfmcosta@gmail.com Lattes: http://lattes.cnpq.br/4410322387790482
}

CONPEDI LAW REVIEW | QUITO - EQUADOR | v. 4 | n. 2 | p. 350 - 371 | JUL - DEZ | 2018 


\section{Introdução}

O estudo objetiva analisar, a partir do estudo epistemológico do Novo Constitucionalismo Latino Americano, as origens histórico-sociais do Direito. Nesse sentido, é demonstrada a epistemologia do Sul como potencial desmistificador do Direito, de caráter Ocidental, constatando-o como uma esfera retórica incapaz de possibilitar novos horizontes à realidade latino-americana. Para tanto, considera-se a historicidade crítica como elemento desmistificador, de forma a demonstrar o direito como fenômeno social e não como uma ciência pura e mitificada. ${ }^{1}$ Nessa trilha, o viés interdisciplinar possibilitou a realização de um resgate de aportes teóricos e reflexões com base no campo sócio-histórico crítico e antropológico, que apontam que a universalização da epistemologia do Norte se trata de uma estratégia colonial e de imperialidade. Portanto, o estudo busca explorar o direito por meio de suas características socio-político-geográfico-culturais e explicar sua incompatibilidade com a realidade do Sul global.

Diante dessas questões, indaga-se: É possível uma fundamentação do Direito a partir das epistemologias do Sul?; Se sim, seria a Constituição um instrumento basilar para tanto?; e, ainda, Quais cosmovisões poderiam ser trazidas para demonstrar o potencial das epistemologias do Sul para quebra paradigmática jurídico-constitucional? A busca por essas respostas evidenciarão os dilemas da modernidade e a necessidade de reavaliarmos elementos que subsidiaram a consolidação do projeto de vida moderno.

Fala-se aqui do Sul como metáfora do sofrimento humano provocado pelo capitalismo e colonialismo globais que, como será demonstrado, advém de fontes epistêmicas ocidentais. Pode ser sintetizada como um aprender com o Sul, usando uma epistemologia do Sul, pois a análise permite evidenciar as potencialidades do novo paradigma para se desenvolver na relação com o Norte. Não se trata de inverter a situação a favor do Sul Global, como se estivesse a ensinar o Norte, como este o fez primeiramente. É muito mais que isso,

\footnotetext{
${ }^{1}$ A elaboração do presente estudo foi pensando em se desenvolver um tema de maneira crítica. A mera descrição dos fenômenos, por si só, não logra essa abordagem. Por isso, a teoria crítica permitirá não só descobrir os diferentes aspectos ocultados na realidade, mas sobretudo, abrirá portas para uma nova dimensão: a da experiência. Assim, a teoria reencontra sua ligação com a prática, com o mundo social existente. Nesse sentido, Dussel (1977), Flores (2009), Santos (2000; 2010), Quijano (2005) compõem o arcabouço teórico utilizado para desenvolver o embasamento científico desse estudo. Isso porque são de significativa influência no rumo teórico da pesquisa que trata da colonialidade, pluralismo jurídico, epistemologias do Sul, direitos humanos, lutas sociais, América Latina. Esses estudos também foram utilizados para analisar a epistemologia constitucional Ocidental de viés positivista e pós-positivista, de forma a evidenciar as matizes do Direito e suas principais incongruências.
}

CONPEDI LAW REVIEW | QUITO - EQUADOR | v. 4 | n. 2 | p. 350 - 371 | JUL - DEZ | 2018 
pois trata-se de ter a criatividade de sermos capazes de construir um novo momento histórico desde a epistemologia do povo latino-americano.

Nessa trilha, a problemática central diz respeito à busca pelo (res)significado do direito latino-americano por meio das epistemologias do Sul Sumak kawsay, Suma Qamaña e Haluhalunekisu. Esta última de origem brasileira, não adotada constitucionalmente. Todas essas cosmologias andinas, as duas primeiras das etnias Kichwa e Aimará, compreendem o ser humano como parte integrante da Natureza, configuradas na noção do Buen Vivir. As epistemologias do Sul possibilitam novas reflexões jurídicas acerca do que se entende por constitucionalismo, direitos humanos, Estado. Essa repercussão no âmbito jurídico-social é estudada no marco do Novo Constitucionalismo Latino-Americano.

Para a análise acerca das constituições plurinacionais e interculturais da Bolívia e do Equador adotou-se diferentes perspectivas e tendências. Isso porque intenta-se um estudo analítico-sociológico, a fim de compreender a conjuntura desses países quando da formação da constituinte, bem como as características culturalista-plurais que fizeram com que emergisse tal anseio popular.

O estudo entende que o Novo Constitucionalismo Latino-Americano trata-se de um processo de transição jurídico-social rumo à descolonialidade. No Brasil existem diversas cosmovisões indígenas que remetem ao Buen Vivir. Dentre as tantas, existe a Haluhalunekisu, mencionada alhures, pertencente à cosmologia Nambiquara, etnia que habita o Oeste de Mato Grosso e o Sul de Rondônia, entre as cabeceiras dos rios Tapajós e Guaporé, áreas de abrangência da Amazônia Legal. Sem que se objetive tornar unitárias ou homogêneas as ricas concepções brasileiras - já que o Novo Constitucionalismo Latino-Americano prima pela expressão somatória de diferentes concepções e perspectivas -, o estudo objetiva compreender e dar visibilidade à Haluhalunekisu. Isso porque Haluhalunekisu permite pensar em uma perspectiva epistemológica brasileira de relação de respeito e integralidade entre todos os seres. ${ }^{2}$ Observa-se que a preocupação com a destruição ambiental/espiritual da Terra é comum nas diferentes epistemologias indígenas que povoam o planeta. Finalmente, cosmologias indígenas começam a ser entendidas como meio de proteção jurídicoepistemológica aos humanos e não-humanos, sob a ótica do Novo Constitucionalismo LatinoAmericano.

\footnotetext{
${ }^{2}$ Para desenvolver a perspectiva da Natureza como sujeito de direitos nas narrativas cosmológicas dos Aimara, Kichwa e Nambiquara, foram utilizados, dentre outros, os estudos de Acosta (2016), Zaffaroni (2010; 2012), Viveiros de Castro (2002), Costa (2002; 2009), Price (1972).
}

CONPEDI LAW REVIEW | QUITO - EQUADOR | v. 4 | n. 2 | p. 350 - 371 | JUL - DEZ | 2018 
Objetivando colmatar a investigação científica ora proposta, a partir de uma pesquisa bibliográfica de caráter interdisciplinar, empregou-se o método hipotético-dedutivo (BITTAR, 2013), direcionado à análise da epistemologia jurídica do Sul e do Norte. Isso em razão da imprescindibilidade em se recorrer a uma pesquisa da experiência histórica do Direito, essencial à compreensão do contexto colonial em que se insere o continente latino-americano.

O estudo proposto foi elaborado com a ideia de desvelar as epistemologias dos povos subalternizados e demonstrar seus potenciais para uma quebra jurídico-paradigmática. Pensou-se na possibilidade de vir a servir como meio de reflexão sobre alternativas jurídicoconstitucionais brasileiras, por meio de cosmologias indígenas, bem como para fortalecimento de lutas sociais. Isso porque são os movimentos sociais que dão origem à transformação do direito. Também tem por escopo romper com as amarras do colonialismo que nos rodeiam e que utilizam formas de opressão e ocultamento de grupos marginalizados, levando-os ao extermínio.

\section{A constituição como instrumento de luta social}

O termo constitucionalismo apareceu no vocabulário jurídico-político há cerca de duzentos anos, com o advento da Constituição Francesa, de 1791, originada pela Revolução Francesa, e da Constituição dos Estados Unidos, de 1787, originada das Revoluções Estadunidenses. Com a ascensão do capitalismo e, posteriormente, com a Revolução Industrial que exigiram respostas mais rápidas do direito às demandas sociais, a lei passou a ser a principal fonte do direito, já no século XIX, direcionando a criação de regras racionais, de forma que proporcionassem "segurança jurídica" e que possuíssem "caráter universal". Ainda que o constitucionalismo liberal-burguês e o Estado Moderno representem um marco jurídico e de luta social contra a ordem medieval, têm como cerne uma epistemologia pautada em um discurso excludente. Isso porque é elaborada por e para determinada classe social ${ }^{3}$ cujos interesses se voltam, basicamente, à proteção da propriedade privada e do mercado, envoltos sob o rótulo de liberdades individuais, abstenções e incentivos estatais. De acordo com Santos (2000, p. 126),

\footnotetext{
${ }^{3}$ Aqui, dá-se início às várias teorias que pretendem estabelecer um marco do Estado monista e justificar a necessidade do Estado moderno, a exemplo de pensadores como Montesquieu, que elaborou a teoria sobre a separação dos poderes, e Thomas Hobbes, John Locke e Jean-Jacques Rousseau, que elaboraram teorias contratualistas. (BOLZAN DE MORAIS; STRECK, 2014).
}

CONPEDI LAW REVIEW | QUITO - EQUADOR | v. 4 | n. 2 | p. 350 - 371 | JUL - DEZ | 2018 
O direito natural racionalista dos séculos XVII e XVIII, também faz parte deste processo, na medida em que serviu para legitimar, quer o despotismo iluminado quer as ideias liberais e democráticas que conduziram à Revolução Francesa, partindo, portanto, do modelo de racionalidade descrita. Portanto, há contrariedade entre os direitos naturais tidos como universais como forma de emancipação social. Dessa forma, tanto a virada Kantiana, como o raciocínio iluminista, o constitucionalismo liberal e, posteriormente, a internacionalização dos direitos humanos fazem parte da mesma faceta colonizadora. $\mathrm{O}$ aprimoramento dos direitos humanos por meio do Welfare-State serviu como forma de gestão capitalista, pois ao Estado providência coube a gestão das desigualdades e à teoria dos direitos humanos a gestão da exclusão.

É possível compreender que, embora a Revolução Francesa tenha substituído o absolutismo pelo Estado Moderno, manteve-se a figura centralizadora do poder, agora, não mais com base no direito Natural, mas por meio do princípio da legalidade ${ }^{4}$. Portanto, o status quo se manteve inalterado desde então, orientado à buscar segurança jurídica e a secularização do poder político. ${ }^{5}$ Esses ideais influenciaram todo o mundo, dando origem ao constitucionalismo e aos Estados modernos.

Na América Latina, há cinco séculos, desde a expansão marítima e comercial, o Norte global propaga seu olhar acerca da história da civilização, democracia, cidadania, constitucionalismo, direitos humanos, organização e limites do Estado. A crença na necessidade de doutrinar o mundo, ditar suas normas e saberes, bem como em estabelecer o que vem a ser progresso e desenvolvimento, são, basicamente, de caráter imperialista e colonialista. Estes ideais andam a par de violências que fazem parte da história europeia e a América do Norte utiliza da mesma estratégia. São muitas as faces da opressão e dominação e várias delas são negligenciadas pelos estudos jurídicos.

Enquanto teóricos debruçam-se acerca da distinção entre princípios e regras, não veem o contexto abissal ${ }^{6}$ em que estas se inserem. Isso porque as razões da crise do

\footnotetext{
${ }^{4}$ Ponto criticado por Ferrajoli (2015), que demonstra que o princípio da legalidade não abarca uma avaliação material da lei. Isso porque, como explica o autor, a noção de que uma norma jurídica existente é considerada válida apenas em decorrência da forma com que foi produzida, a desvincula da essencial noção intrínseca de justiça, pois leva em conta, apenas, o procedimento com que foi editada e a legitimidade de quem a editou.

${ }_{5}^{5}$ Esse cenário configura o "Mito da Lei" (PEREIRA, 1999. p. 131) que considera a lei como único instrumento capaz de proporcionar liberdade aos cidadãos e impor-lhes um pacto social de deveres e direitos.

${ }^{6} \mathrm{O}$ pensamento moderno ocidental é abissal, pois baseia-se em um sistema de distinções entre visível e invisível que dividem a realidade social em dois universos distintos: "deste lado da linha" e "do outro lado da linha". A distinção ocorre na medida em que "o outro lado da linha" desaparece como realidade, se produzindo apenas como ausência, invisibilidade, inexistência. A característica principal desse pensamento é a impossibilidade da co-presença dos dois lados da linha. As representações mais cabais são o Conhecimento e o Direito modernos.
}

CONPEDI LAW REVIEW | QUITO - EQUADOR | v. 4 | n. 2 | p. 350 - 371 | JUL - DEZ | 2018 
positivismo são similares as do pós-positivismo, pois ambos permitem barbáries em nome da lei, por serem incapazes de compatibilizar o Direito positivado à realidade social. Assim, a constituição configura mais um documento político do que propriamente um instrumento jurídico emancipador. O ocidentalismo se supõe fonte epistêmica de conhecimento, como que superior às demais, desprezando saberes do mundo e outras espiritualidades, taxando-as de inferiores ante à imposta razão científica do homem ocidental. Isso resulta na racionalização da ciência do Direito a uma visão universal de valores, modelos e definições que refletem a própria existência do ocidental. É justamente na percepção do Outro enquanto "primitivo", "bárbaro", "arcaico", "tradicional”, "simples" ou "selvagem" que o Ocidente vem produzindo a imagem e a reafirmação de si mesmo. O conceito colonial ocidental de modernidade colocou a América Latina em lugar periférico, rotulando o continente em "subdesenvolvido" ou "em desenvolvimento", evidenciando uma "ontologia da totalidade" (SOUSA, 2014). Daí a relevância em se desenvolver relações recíprocas e igualitárias, com fundamentos descoloniais.

Nessa trilha, o desvelar das epistemologias do Sul, de forma que não sejam vistas como inferiores às do Norte Global, permite conhecer o potencial epistemológico-jurídico proporcionado por elas. Assim, as formas jurídicas dominantes de viés epistemológico ocidental podem continuar a existir e reproduzir-se, embora, sem o monopólio sobre as práticas epistemológicas e sociais, pois todos os conhecimentos fazem parte de uma amálgama, uma "ecologia de saberes" (SANTOS, 2010, p. 137). No entanto, uma pergunta mostra-se pertinente: $\mathrm{O}$ direito pode ser uma ferramenta legítima para emancipar ou liberar? Diante do "Mito da Lei", por que continuar falando em constitucionalismo? A resposta a essa pergunta não se trata de uma opção pessoal, mas sim da postura político-social dos movimentos populares que demonstra a possibilidade de transformar mecanismos ocidentais em instrumentos de luta, ainda que estes não reflitam a identidade e trajetória latinoamericana. As constituições do Equador e da Bolívia são exemplos disso ${ }^{7}$, pois são instrumentos que portam anseios populares traduzidos nas epistemologias do Sul,

Eles formam as duas principais linhas abissais globais dos tempos modernos e são interdependentes. (SANTOS, 2000).

${ }^{7}$ Em contextos nacionais diferentes, o Equador e a Bolívia convocaram assembleias constituintes, as quais desenvolveram declarações aprovadas pelo povo em 2008 e em 2009, respectivamente. Ambas as constituições foram aprovadas por meio de referendo constitucional. Para saber mais a respeito desses contextos, consultar Ávila Santamaria; Grijalva Jimenez; Martinez Dalmau (2008); Llasag Fernández (2014); Martinez Dalmau; Leoneu Júnior (2014).

CONPEDI LAW REVIEW | QUITO - EQUADOR | v. 4 | n. 2 | p. 350 - 371 | JUL - DEZ | 2018 
proporcionando plurinacionalidade e interculturalidade como alternativas de organização social, política e econômica.

As lutas sociais emergidas no Equador e na Bolívia questionavam ${ }^{8}$ : o constitucionalismo que legitimava um sistema colonial, excludente, assimilacionista, patriarcal, capitalista e monocultural, fruto das "independências"; a falta de compatibilidade normativa com a realidade latino-americana e propiciadora de exclusão e marginalização da coletividade indígena, afrodescendentes, mulheres, crianças; a apropriação da Natureza como objeto de exploração; o sistema de ensino e a produção de conhecimentos, incapazes de desenvolver indivíduos críticos, de forma a torna-los facilmente submissos ao sistema e alheios à realidade latino-americana, uma vez que invisibiliza conhecimentos tão válidos quanto ao que se entende por "ciência"; o sistema estatal e social racista, baseados em estereótipos sobre indígenas, afrodescendentes; a família pautada em uma visão patriarcal na qual a mulher é inferior e incapaz; a relação colonial com outros países; a importação de institutos normativos pautados em uma teoria política incompatível com a realidade política dos países latino-americanos. ${ }^{9}$ (LLASAG FERNÁNDEZ, 2014).

$\mathrm{O}$ projeto era consciente de que alternativas poderiam ser encontradas em epistemologias marginalizadas, excluídas e invisibilizadas, em especial, as dos movimentos indígenas. Por isso, esse processo vai muito além da refundação do Estado, trata-se de efetivar a superação do colonialismo, do neocolonialismo e da noção de desenvolvimentismo a nível local, regional e internacional. O fato do projeto inovador advir das epistemologias do Sul, fez com que, a princípio, fosse visto como separatista, divisionista ou mesmo invisibilizado. Foi a pressão popular que conseguiu que se instituísse o processo de refundação dos Estados, ou seja, de transformação dos Estados coloniais, capitalistas, patriarcais e monoculturais em Estados plurinacionais e interculturais, inaugurando o marco constitucional de transição que concebe a organização social, política e econômica com características latino-americanas. As epistemologias do Sul constitucionalmente reconhecidas, significa não mais desprezar a identidade de seu próprio povo, a existência de outras formas de conceber o mundo e de reger

\footnotetext{
${ }^{8}$ Protestos indígenas da década de 1990 que exigiam a convocação de uma assembleia constituinte para elaborar uma Constituição que declarasse formalmente os Estados como multiculturais e pluriétnicos. (LLASAG FERNÁNDEZ, 2014).

${ }^{9}$ A exemplo disso, pode-se citar a forma geográfica Ocidental com que os países são divididos. Os países latinoamericanos não se inserem nesse ideal liberal de Estado-nação, ainda que constituições latino-americanas concebam seus Estados nacionais como monoculturais. Isso porque, na prática, os Estados são heterogêneos e pluriculturais, principalmente em decorrência do grande número de etnias aqui presentes.
}

CONPEDI LAW REVIEW | QUITO - EQUADOR | v. 4 | n. 2 | p. 350 - 371 | JUL - DEZ | 2018 
relações. A pressão social, porém, exigiu que a multiculturalidade ${ }^{10}$ fosse reconhecida como característica do modelo neoliberal. Diante dessa realidade, os movimentos indígenas, articulados com outros segmentos sociais, pressionaram para que fosse viabilizada a proposta de Estado plurinacional e intercultural. Uma vez aprovadas as constituições da Bolívia (2009) e do Equador (2008), foram realizados diversos estudos em diferentes perspectivas, pois as artimanhas coloniais continuam se repetindo. Isso decorre do fato de serem ignoradas tanto as visões como as concepções das epistemologias do Sul, ainda que constitucionalmente compreedidas. De acordo com Llasag Fernández, e essa é a tese aqui adotada, essas Constituições são a parte formal do que preparará para o processo de transição Estatal, compreendendo-as, portanto, como "constituições de experimentação" (2014, p. 267). Portanto, o caminho para a efetivação desse projeto social é longo, mas já está em percurso.

A constituição pode ser um instrumento transformador da realidade, mas há pressupostos que devem ser considerados e analisados. Para tanto, sua concepção e fundamentos devem estar atrelados ao contexto de lutas sociais de movimentos latinoamericanos, bem como à análise crítica das epistemologias que é possível abarcar, tanto as do Sul quanto às do Norte global. Isso é possível por meio de análises históricas, uma vez que desistoricizar implica conceber o direito apartado da realidade, como fórmula pura, neutra, imparcial, universal, racional. A epistemologia ocidental invisibiliza a história, as suas lutas sociais e as epistemologias latino-americanas. Esse ocultamento resulta na colonização e opressão da América Latina, de forma que ignorar ou desprezar as epistemologias do Sul implica em deixar o latino-americano oco e passível de dominação e não-identificação.

De acordo com Freire e Faundez (1985), mesmo após séculos da chegada do colonizador, este deixa sua herança cultural e ideológica embrenhada na mente do dominado, de forma a fazer parte dele. Essa redução a uma única forma de ver a realidade é denominada por Mignolo (2009) de "privilégio epistémico da modernidade", geradora e mantenedora da colonialidade do conhecimento e da subjetividade do ser. Portanto, "Historizar é humanizar; e nada no humano é estático ou procede de alguma ordem transcendental.” (FLORES, 2009). Todo fenômeno social decorre de uma causa histórica. Ademais, não é possível analisar a ciência jurídica se não a compararmos com outras formas de direito, de maneira a constata-la

\footnotetext{
${ }^{10}$ Walsh (2008, p. 140) esclarece que o prefixo "multi" designa várias culturas singulares em relação entre elas, prevalecendo uma dentre elas. Esse prefixo tem suas raízes em países ocidentais. O prefixo "pluri" indica uma convivência de culturas em um mesmo espaço territorial. Já a interculturalidade trata-se de um conceito mais amplo, pois indica "un proceso y proyecto social político dirigido a la construcción de sociedades, relaciones y condiciones de vida nuevas y distintas".
}

CONPEDI LAW REVIEW | QUITO - EQUADOR | v. 4 | n. 2 | p. 350 - 371 | JUL - DEZ | 2018 
como fenômeno sociocultural advinda de lutas sociais emersas em determinadas localidades.

Somente assim desmistifica-se os marcos relacionados ao fenômeno do direito. Nesse sentido, é imprescindível desenvolver concepções

que tenham em conta as diferentes formas de perceber, narrar e atuar no mundo; ou seja, as diferentes formas de lutar por uma vida digna de ser vivida. Por conseguinte, necessitamos urgentemente ampliar nosso conhecimento a respeito do que outras culturas entendem pela dignidade humana. Precisamos realizar algo como uma "leitura contrapontística", na qual diferentes vozes sejam escutadas e levantadas em consideração como um recurso público de enorme importância para visualizar que não é tão clara a contraposição entre "civilização" e "barbárie". (FLORES, 2009, p. 129-130).

Assim, mostra-se exequível a apropriação e reformulação do direito por grupos subalternizados para se defenderem, inclusive, do próprio direito. Portanto, a resposta dada pelas lutas sociais demonstra que não é necessário que a América Latina abdique de instrumentos simplesmente por serem de origem epistemológica ocidental, desde que os concebamos sob óticas capazes concede-lo uma nova identidade, uma identidade latinoamericana. Consequentemente, efetiva-se maior aproximação dos instrumentos normativos à realidade continental latino-americana. O constitucionalismo pode ser uma ferramenta útil ao diálogo e à emancipação, capaz de transformar e alterar a realidade e o status quo.

\section{A Natureza como sujeito de direito: perspectivismo no Novo Constitucionalismo}

\section{Latino Americano}

As inovações trazidas pelo marco do Novo Constitucionalismo Latino Americano buscam uma concepção de Estado e de sociedade que supere o colonialismo, o patriarcado ${ }^{11}$, que permita uma leitura intercultural do direito constitucional ${ }^{12}$ e que os historicamente excluídos e marginalizados sejam os protagonistas dos processos constitucionais, de forma que a constituição seja o reflexo da sociedade em sua pluralidade e interculturalidade. Esse marco constitucional é mais do que um projeto de efetivação do Buen Vivir. Trata-se da busca

\footnotetext{
${ }^{11}$ As constituições da Bolívia (2009) e Equador (2008) não generalizam homens e mulheres em "indivíduo" ou "homem" (sempre no singular e no masculino). Isso pode ser compreendido como uma forma de evidenciar a diferença e luta entre "homens" e "mulheres".

12 Outro ponto importante é o reconhecimento da diversidade nacional enquanto homens, mulheres, povos, comunidades, nações (artigo 3 da constituição da Bolívia, por exemplo).
}

CONPEDI LAW REVIEW | QUITO - EQUADOR | v. 4 | n. 2 | p. 350 - 371 | JUL - DEZ | 2018 
por rompimento com categorias constitucionais pós-coloniais ${ }^{13}$, de forma a implementar ações de caráter descolonial. ${ }^{14}$ Para fins desse estudo, qual seja, demonstrar a importância das epistemologias constitucionais do Sul, voltamos a análise para o último ciclo de Yrigoyen Fajardo $(2011)^{15}$, especificamente no que tange às cosmologias andinas adotadas pelas constituições do Equador (2008) e da Bolívia (2009). Isso porque essas constituições utilizam de epistemologias indígenas, possibilitando uma revisão crítica de dogmas constitucionais ocidentais tidos como intangíveis e mostrando alternativas ao desenvolvimento econômico, político e social dominantes.

Essas constituições rompem com modelos ocidentais ao incorporarem saberes nãoliberais em seus textos, tais como o Sumak kawsay e o Suma Qamaña que objetivam proteção à Pachamama ${ }^{16}$. Sumak Kawsay e Suma Qamaña são valores indígenas que não possuem tradução nas línguas coloniais. O significado mais próximo é Buen Vivir, não possuindo conotação a um viver bem utilitarista. Sumak Kawsay é uma expressão Kichwa consagrada pela Constituição equatoriana. Sumak significa o ideal, o belo, o bom, realização, plenitude; Kawsay quer dizer viver, vida digna, harmonia e equilíbrio entre o universo e o ser humano. A postura biocêntrica do Equador, ao conceber a Natureza como sujeito de direitos, demonstra uma alternativa ética. (Acosta, 2016). Similar à Sumak Kawsay, Suma Qamaña é uma expressão etnia boliviana Aimará. Refere-se ao Buen Vivir, relacionado à ideia de olhar o passado, viver o presente, para projetar o futuro como sonho de vida plena. (ZAFFARONI, 2010). A positivação do Sumak Kawsay e do Suma Qamaña instauram um novo marco

\footnotetext{
${ }^{13} \mathrm{O}$ pós-colonialismo é um período posterior à colonização, com a declaração de independência dos países, mas ainda na contemporaneidade há forte dependência entre colonizadores e ex-colônias, por meio da colonialidade do ser, do saber e do viver, pautados na universalização da epistemologia do Norte (QUIJANO, 2005).

${ }^{14}$ Descolonialismo trata-se de um pensamento crítico baseado na noção de ruptura com todas as formas de colonialismo existentes no pós-colonialismo, a exemplo da teoria crítica clássica eurocêntrica. Enrique Dussel (1977), Anibal Quijano (2005) são autores críticos que buscam um desvelar latino-americano. A busca por essa teoria crítica baseada na identidade latino-americana resulta na averiguação de características marcantes de nosso continente: alteridade, pluralidade e interculturalidade. Walter Mignolo (2009) e Catherine Walsh (2008) adotam a terminologia "decolonialismo".

15 Yrigoyen Fajardo (2011) demonstra o constitucionalismo latino-americano em três principais ciclos: "constitucionalismo multicultural" (1982-1988); "pluralismo jurídico subordinado colonial" (1989-2005); "constitucionalismo plurinacional" (2006-2009). Esse último intenta conceder um caráter intercultural às normas constitucionais. Como resultado das lutas sociais e do protagonismo indígena marcante nesse período que buscavam um projeto descolonizador e intercultural para o país, internalizou-se cosmovisões indígenas à constituição, ocasionando um giro paradigmático na teoria da Constituição. Nesse ciclo, inserem-se as constituições do Equador (2008) e da Bolívia (2009).

${ }^{16}$ Deidade máxima dos Andes, protetora da natureza, cujo nome Quéchua significa Mãe Terra. Esse ser espiritual exige respeito e cooperação dos demais seres para com ela. Sua consagração pela Constituição do Equador (artigo 71), objetiva respeito aos ciclos naturais ecológicos, o que implica na tentativa de rejeição da teoria utilitarista dos recursos naturais sobre a qual se alicerça o capitalismo. (ZAFFARONI, 2010).
}

CONPEDI LAW REVIEW | QUITO - EQUADOR | v. 4 | n. 2 | p. 350 - 371 | JUL - DEZ | 2018 
epistemológico constitucional, sendo essas constituições as mais avançadas para o processo de descolonização. Proporcionam um giro paradigmático ao afastar o modelo constitucional ocidental antropocêntrico para vigorar um biocêntrico de dignidade ${ }^{17}$.

O reconhecimento da Natureza como sujeito de direitos demonstra que o meio ambiente possui valor intrínseco, ontológico, com um fim em si mesmo e não voltado para a saúde e para o "Bem-Estar" humano (concepção de natureza contida no marco da epistemologia constitucional do Norte, de caráter puramente liberal). A epistemologia do Norte compreende o homem/indivíduo como ser racional e, por essa "razão", difere-se dos demais seres do planeta, como se nada fosse "humano", exceto nós, sozinhos, especiais, superiores a habitar o Universo e a utilizar dos recursos naturais como se fossem infindos. Já a epistemologia do Sul não vê diferença entre os seres que habitam a Terra, pois animais e plantas, ainda que se utilizem dessas roupagens, possuem uma essência/“alma" "humana". Portanto, nessa perspectiva, tudo é "humano", todos compartilham e buscam equilíbrio (Buen Vivir) no ambiente em que vivem (Sumak Kawsay e Suma Qamaña).

Ao explorar o pensamento indígena, Viveiros de Castro (2002) aborda a cosmologia ameríndia dos diferentes sujeitos, "humanos" e "inumanos", constante nas normativas cosmológicas. Conforme sua explicação,

\begin{abstract}
Os animais são gente, ou se vêem como pessoas. Tal concepção está quase sempre associada à idéia de que a forma manifesta de cada espécie é um envoltório (uma 'roupa') a esconder uma forma interna humana, normalmente visível apenas aos olhos da própria espécie ou de certos seres transespecíficos, como os xamãs. Essa forma interna é o espírito do animal: uma intencionalidade ou subjetividade formalmente idêntica à consciência humana, materializável, digamos assim, em um esquema corporal humano solto sob a máscara animal. (VIVEIROS DE CASTRO, 2002, p. 351)
\end{abstract}

Assim, ecossistemas, florestas, montanhas, neves, animais, plantas, artefatos, possuem mantenedores espirituais, uma essência que possui vontades e que é capaz de interferir no cotidiano da aldeia e para além dela. Por isso, inclusive, que a construção de estradas e de hidrelétricas que perpassam lugares habitados por esses seres espirituais acabam por refletir no mundo físico e espiritual. Também por isso que são compreendidos e respeitados pelas cosmologias indígenas. A capacidade dos espíritos e, eventualmente, dos

\footnotetext{
${ }^{17}$ Segundo Zaffaroni (2012), o biocentrismo afirma o direito à dignidade de todos os seres vivos, incluindo os não humanos, sendo, portanto, uma alternativa ao modelo normativo antropocêntrico.
}

CONPEDI LAW REVIEW | QUITO - EQUADOR | v. 4 | n. 2 | p. 350 - 371 | JUL - DEZ | 2018 
pajés em adquirirem formas corpóreas diferentes constitui em um importante foco de interesse dos índios, pois dela pode depender/anunciar/transmitir desígnios e o encaminhamento/anunciamento de interesses. Viveiros de Castro (2002, p. 381) recorre ao etnólogo Lévi-Strauss para exemplificar:

Se o corpo é o que faz a diferença aos olhos ameríndios, então se compreende, afinal, por que os métodos espanhóis e antilhanos de averiguação da humanidade do outro, na anedota narrada por LéviStrauss, mostravam aquela assimetria. Para os europeus, tratava-se de decidir se os outros tinham uma alma; para os índios, de saber que tipo de corpo tinham os outros. O grande diacrítico, o sítio da diferença de perspectiva para os europeus é a alma (os índios são homens ou animais?); para os índios, é o corpo (os europeus são homens ou espíritos?).

Conceber, constitucionalmente, outras formas de ser e perceber o mundo consiste em reconhecermos a condição a nós apregoadas pela epistemologia do Norte como latinoamericanos oprimidos, colonizados, invisibilizados, "subdesenvolvidos", "bárbaros", "primitivos", "tradicionais". Trata-se de posicionarmos contra qualquer forma de colonialidade do ser, saber, viver (QUIJANO, 2005). Por isso, faz-se necessário o desvelar das epistemologias do Sul, pois é aí que encontraremos as alternativas rejeitadas e invisibilizadas pela epistemologia do Norte. Nesse sentido, o Direito latino-americano é capaz de cumprir seu papel de refletir e atender aos anseios da realidade, ao abarcar a pluralidade de perspectivas cosmológicas. Daí que o Novo Constitucionalismo Latino Americano dá um salto consubstancial ao conceber a Natureza como sujeito de direitos, pois reconhece o potencial das epistemologias do Sul para romper com paradigmas coloniais do Norte global.

\section{Epistemologia Nambiquara: a procura por alternativas descoloniais no Brasil}

Ainda que as epistemologias do Sul sejam importantes ao processo de descolonização da América Latina, o Brasil nunca adotou constitucionalmente uma. De acordo com Brandão (2015), a atual constituição brasileira, promulgada em 1988, não é considerada um exemplo no marco do Novo Constitucionalismo Latino-Americano. Isso porque, além da não adoção de epistemologias do Sul, não houve participação ou consulta popular para ativação do poder constituinte, durante o processo de elaboração, bem como na ratificação do projeto final da Constituição, o que configura um déficit de legitimidade 
democrática. Além disso, o contexto histórico-social em que foi elaborada foi logo após um intenso período de ditadura militar, tendo representantes militares participado do processo constituinte.

Já em termos epistemológicos brasileiros, existem diversas cosmovisões indígenas capazes de proporcionar um giro jurídico-paradigmático, em sentido similar ao Buen Vivir. Dentre as tantas etnias, encontram-se os Nambiquara ${ }^{18}$, um povo que habita o Oeste de Mato Grosso e o Sul de Rondônia, entre as cabeceiras dos rios Tapajós e Guaporé, áreas de abrangência da Amazônia Legal. Os Nambiquara vivem em pequenas aldeias, organizando-se de forma a não degradar nem desrespeitar os demais seres da Natureza. Se atentam a não cansar o solo destinado às roças de toco e a não esgotar os recursos naturais da coleta, da caça e da pesca, atividades que nutrem a vida material e espiritual. Dividem-se em vários grupos, todos com suas autodenominações, distribuídos em três ecossistemas distintos: Serra do Norte, Vale do Guaporé e Chapada dos Parecis. Neste último, localizam-se os grupos Kithãulhu, Sawentesu, Wakalitesu e Halotesu, conhecidos como Nambiquara do Cerrado, cuja epistemologia é objeto deste estudo. (COSTA, 2002; 2009). ${ }^{19}$

Contam os Nambiquara do Cerrado que no início do universo, houve um dilúvio ${ }^{20}$ ocasionado pela ação do espírito Waluru, destruindo o mundo. Tempos depois, o Sol, iraladndekisu, e a lua, ilakisu, reapareceram. Não existiam mais humanos, apenas animais. No entanto, no interior de uma montanha em formato de pedra chamada txahlxisu, sobrevivia um grupo de Nambiquara. Esses índios viviam em constante alegria, fartura de alimentos e desconheciam a doença e o envelhecimento. Do lado de fora, viviam animais e outras espécies de seres vivos que podiam ouvir vozes que vinham do interior dessa montanha. Alguns, aguardavam que alguém saísse. O macaco japuçá, hosxasitisu, esperou tanto que a pelagem de seu lombo chegou a ficar avermelhada. Resolveu chamar a cutia para roer a pedra

18 De acordo com Price (1972) e Costa (2009), na literatura, até hoje, são erroneamente chamados de Nambiquara, um nome genérico e alheio ao conjunto de palavras que dispõe seu idioma, considerado isolado, sem quaisquer ligações com as línguas faladas em toda a América Latina. Também são conhecidos pela alcunha de "povo das cinzas" (CARELLI; SEVERIANO, 1980), por terem o hábito de dormirem diretamente no chão, sobre as cinzas da fogueira.

${ }^{19} \mathrm{O}$ presente estudo restringe-se à análise cosmológica dessa etnia, não se aprofundando em questões referentes às suspensões e às faltas de demarcações de suas terras. Restringe-se a mencionar que a situação em que se encontram é comum à maioria das etnias brasileiras, ainda que a Constituição Federal de 1988 tenha estabelecido que todas as terras indígenas fossem demarcadas dentro de 5 anos, contados da data de promulgação da constituição (artigo 67). Passaram-se 30 anos e os empasses para demarcações de terras indígenas são cada vez maiores. Diante das ações das frentes de expansão econômica, o universo indígena está constantemente sendo desrespeitado, configurando uma estratégia de colonialidade.

${ }^{20}$ A água está muito presente nas narrativas Nambiquara, ora como indicativo de morada de espíritos, ora em cataclismos (COSTA, 2009). 
com seus dentes afiados. Porém, não resistiram à solidez. Pediu à anta que, inutilmente, tentou quebra-la. O tatu canastra, com seu casco áspero, saiu ferido ao tentar lixa-la. O urubu, com voos longínquos, não conseguiu perfura-la com seu bico. Foi quando a andorinha da mata, kualihahaitalisu, uma mulher-espírito, ${ }^{21}$ também curiosa para descobrir quem habitava aquela enorme pedra, com uma lança, voou longe adquirindo embalo, quando conseguiu abrila. Dela saíram várias pessoas que foram morar em determinadas direções apontadas pela andorinha. (COSTA, 2002; 2009).

A cartografia apresentada por Costa (2009) expõe lugares espirituais, habitados por diversas entidades que interagem entre si e com os índios, com pontos de vistas e perspectivas próprias. Invisíveis aos olhos comuns, se mostram ao wanintesu (pajé) ${ }^{22}$ com hábitos antropomórficos correspondentes aos mitos revelados pela tradição oral. Animais se veem e são vistos como gentes numa relação de predação, onde a perspicácia de um grilo pode dominar uma onça. Assim, o mundo Nambiquara concebe diferentes perspectivas: o que se apresenta como larva de carniça aos olhos humanos, para o urubu é igual ao amendoim que o índio come (COSTA, 2009).

Para os Nambiquara, "montanhas" ou "buracos" existentes em seu território são moradias de "donos" de determinadas espécies de animais. Os rios, renomeados pela cartografia oficial, influenciam as ocupações territoriais pelos Nambiquara, pois podem pertencer à moradia de inúmeros seres fantásticos. ${ }^{23} \mathrm{O}$ foco das atenções dessa etnia são as "Montanhas Sagradas" ou "Casa das Almas", um complexo que morros que abriga espíritos ancestrais e outros seres. Localizada entre as nascentes dos rios Preto/Adowina e Arimena/Olowina, os Nambiquara acreditam que é para lá que suas essências/almas seguem

\footnotetext{
${ }^{21}$ Fontes orais trazidas por Oberg (1953, p. 96) contam que foi "um pica-pau preto e branco" o responsável por quebrar a "pedra preta chamada yahaindurukatsu, situada ao norte da linha de telégrafo, perto de Campos Novos $[\ldots] . "$

${ }^{22}$ Embora não seja comum, o pajé pode ser uma mulher, wanintakalosu (COSTA, 2009, p. 326).

${ }^{23}$ As águas abrigam espíritos maléficos, alguns de hábito antropofágico. A água "[...] é a substância que melhor se oferece às misturas, a noite vai penetrar as águas, vai turvar o lago em suas profundezas, vai impregná-lo. Às vezes a penetração é tão profunda, tão íntima que, para a imaginação, o lago conserva em plena luz do dia um pouco dessa matéria noturna, um pouco dessas trevas substanciais." (COSTA apud BACHELARD, 2009, p. 220). "[...] 'todo rio tem espírito de peixe', 'toda cachoeira tem animal', essa hidrografia encantada representa a morada de muitos seres sobrenaturais, em especial, do casal de peixes Kikayãulhu e Kikayãuli. Essa espécie pode estar em vários córregos e rios, pois lhe cabe a capacidade da reprodução. [...] se sai fora d'água, ele morre. [...] Tem mão de gente. É perigosa. Se ela morrer, morre peixe, seca água, diminui água. Tem homem e tem mulher. Ela é dona do rio, do peixe, tracajá e jacaré. Também gosta de água suja. O pajé pode ir lá para cantar para ele para não ficar triste, mas é muito perigoso" (COSTA, 2009, p. 216-217). O canto do pajé alegra Kikayãuli, pois "ao agredir sua morada com a derrubada das matas próximas às corredeiras e cachoeiras, ele pode ficar triste e vir a falecer." (COSTA, 2009, p. 217).
} 
após a morte. Os moradores desse conjunto de morros usam indumentárias tradicionais e mantém comportamentos semelhantes aos dos vivos: dançam, cantam e celebram a felicidade de estarem juntos. Entendem que só podem adentrar esses lugares se forem alegres em vida! (COSTA, 2009).

É possível constatar que "No mundo material há a prevalência da figura masculina na orientação das atividades cotidianas que se contrapõe à feminina, e esta, ao contrário, destacase no espiritual, conforme os relatos dos wanintesu e demais índios." (COSTA, 2009, p. 353). Os vegetais, a exemplo do buriti e do pequi, também possuem entidades mantenedoras ${ }^{24}$ cujas vontades devem ser respeitadas. Esses seres podem adquirir outras formas/roupagens, inclusive a humana, pois abrigam em seu interior essência análoga às pessoas, podendo falar, cantar, comer, dançar. Alguns, inclusive, possuem artefatos (armas, adornos, objetos) iguais aos dos índios. Entre seus pares, se veem como pessoas e somente o pajé tem a faculdade de descortinar sua verdadeira aparência, interagir com eles e, a depender de sua força, submetêlos à sua vontade.

[...] a ligação homem-vegetal-animal estabelecida nesses dois espaços - visível e invisível -, onde a passagem de um para o outro se transpõe por um fio extremamente tênue, diversas narrativas mitológicas demonstram que humanos, espécies vegetais e animais, além de dividirem o mesmo espaço, comunicam-se. Mesmo que seja adotada uma forma diferenciada de linguagem, compreensível apenas ao wanintesu, ligam-se por afinidade, grau de parentesco e até por amor. (COSTA, 2009, p. 330).

Os pajés são os mais habilitados para identificar as espécies/categorias de espíritos que transitam pelo seu universo. Estão constantemente em perigo, pois "pagam bem caro pelo privilégio de serem reconhecidos como árbitros do infortúnio alheio.” (DESCOLA, 2006, p. 390). Além de sua esposa humana, unem-se a uma mulher-espírito, se essa o escolher, tendo a liberdade de deixá-lo se ele lhe causar alguma dor, não satisfazerem seus gostos alimentares ou em decorrência de condutas ruins como relacionamentos extraconjugais. Ela nunca morre, não envelhece, nunca se casam. Dessa união ela se torna mulher-pajé, wanintakalosu, e ensina músicas e conhecimentos fitoterápicos ao wanintesu. Se dá muito bem com a esposa-humana do pajé, pois ambos sabem que sua companhia traz proteção contra espíritos sobrenaturais maléficos. As relações sexuais entre o pajé e a mulher-espírito proporciona fartura à aldeia,

\footnotetext{
${ }^{24}$ Existe a Moça do Pequi ou Mulher do Pequi que, de acordo com Price (1989, p. 686), é “[...] uma jovem bonita que mora na Aldeia dos Espíritos, com outros Espíritos Eternos."
}

CONPEDI LAW REVIEW | QUITO - EQUADOR | v. 4 | n. 2 | p. 350 - 371 | JUL - DEZ | 2018 
bem como o nascimento de uma criança-onça que acompanhará o pajé até sua morte, momento em que ambos passarão a habitar a Montanha Sagrada.

O wanintesu é o "construtor do mundo Nambiquara” (COSTA, 2009, p. 352), pois é interlocutor e responsável pela intermediação das vontades dos seres. Além de outras atribuições, o wanintesu é responsável pela mediação e interpretação de sonhos e das vontades dos seres, como uma "política cósmica" (VIVEIROS DE CASTRO, 2002). Por ser o mantenedor da ordem social e espiritual, conduz os rituais de cura dos males e dos infortúnios de seu povo. Uma das tarefas mais complexas é a de cuidar da Figueira Haluhalunekisu. Halu, halu é o choro da mulher-espírito, dona desse vegetal. Price (1972, p. 603-609) várias vezes faz menção a essa árvore como "a grande árvore do mundo". Miller (2007, p. 155-156) chama-a de "halohalodu" e "a árvore que segura o céu". De acordo com Costa (2009, p. 199),

Os Nambiquara creem que na abóboda celestial existe uma enorme Figueira, Haluhalunekisu, de imensas raízes envolvendo a terra de todos os homens. Halu, halu representa o choro da mulher-espírito, dona da Figueira nativa, encontrada com regularidade nas matas ciliares do território dos Nambiquara do Cerrado; nekisu significa árvore. Assim, Haluhalunekisu é a "árvore do choro". Dauasununsu, ser sobrenatural, conhecedor de todas as coisas, reina nesse frondoso vegetal de copa verdejante.

Na Haluhalunekisu mora o Dauasununsu, ser sobrenatural conhecedor de todas as coisas. Aves e curiangos, também habitantes da Halu são responsáveis por frequentar a Terra a fim de procriarem nas estações chuvosas, retornando à Figueira somente quando seus filhotes estiverem crescidos. As libélulas, watitinsu, com o passar do tempo, aprenderam a fazer chover na quantidade suficiente a fim de não causarem novos dilúvios. (PEREIRA, 1973). ${ }^{25}$ Há também walulatasu, um tatu destruidor do mundo, que tenta devorar as raízes desse frondoso vegetal. Tem também o urubu e, em sua copa, o gavião, dautatasu, temido pelos seres que habitam Halu e por experientes wanintesu. O gavião possui poder mágico cuja pena, cedida ao wanintesu, transfere poderes e enfeita seu rosto. A narigueira emplumada com a pena de dautatasu confere-lhe a faculdade de voar e viajar até a copa de Halu. O choro do filhote de dautatasu denuncia a necessidade de limpeza para revitalização da árvore. Por isso,

\footnotetext{
25 “[...] o mundo dos Nambiquara já acabou por várias vezes: uma ocasionada pela ação de Walulatasu, um tatu sobrenatural, que de tanto fazer buracos nas margens dos rios provocou uma inundação, e a outra, causada pelos watitinsu [libélulas], que ao baterem incessantemente suas patas na lagoa de Haluhalunekisu provocaram a submersão do mundo Nambiquara." (COSTA, 2009, p. 200). Na descrição de Oberg (1953), é dinínuwa, um pequeno pássaro vermelho, o responsável pelo dilúvio, em decorrência do excesso de sua urina que, ao transbordar, faz chover na Terra.
}

CONPEDI LAW REVIEW | QUITO - EQUADOR | v. 4 | n. 2 | p. 350 - 371 | JUL - DEZ | 2018 
wanintesu, ao alcançar a copa da Figueira para renovar seus poderes junto a Dauasununsu, além de receber os nomes das crianças que estão para nascer, possui a tarefa de limpeza da Haluhalunekisu.

Para os Nambiquara, a purificação de Haluhalunekisu faz-se necessária para o equilíbrio do mundo dos índios e não indígenas. Essa tarefa é instigada pelo repertório musical de wanintesu, entoado nas sessões noturnas de cura. "O filhote de gavião está chorando" porque "debaixo dela está muito sujo". Essa impureza refere-se aos desacertos relacionados às atitudes dos habitantes da Terra. Com o enfeite nasal de pena, viaja para a copa da Figueira. Na visão dos Nambiquara, o mundo só voltará ao normal quando o ser mítico, representado pelo tatu, interromper o desmoronamento ocasionado pela ação do wanintesu. A noção de que o lugar dos homens está "muito sujo" demonstra também como os Nambiquara leem a destruição ambiental. O mito, nesse caso, foi decodificado pelos índios para explicar determinados fatos que estão ocorrendo no mundo dos kwajantisu, os não indígenas. (Costa, 2009, p. 202).

Na cosmologia Nambiquara, é importante satisfazer os desejos de Dauasununsu, que "preza pela alegria, bondade e beleza, caso contrário, castigará a todos, indistintamente, com a escuridão. Os primeiros sinais da insatisfação furiosa de Dauasununsu refletem nas folhas de sua copa, quando elas começam a amarelar e, consequentemente, a cair" (COSTA, 2009, p. 204). Em entrevista realizada por Costa (2009, p. 204) a Jaime Halotesu, este explicou que

Essa Haluhalunekisu é um tipo de árvore. Tem homem branco, tem homem índio, quase igualzinho. Mas, não é igualzinho não. Lá tem a vida! No meio disso, uma folha da vida. Quando amarela, algumas folhas caem. Lá na árvore da vida nunca acontece isso. Sempre saúde. Se alguma folha da árvore da vida amarelar, dá problema, doença. Não é só doente não! É quando a folha, a da vida, amarelar e secar, não é boa coisa não! Você não traz sabedoria não. Só traz miséria. De modo geral, para todo o mundo. Não é só para índio não!

Observa-se que a destruição ambiental/espiritual da Haluhalunekisu e da Pachamama é uma preocupação analogamente presente em diferentes epistemologias indígenas que povoam o planeta. Finalmente, essa concepção começa a ser entendida como meio eficaz de proteção jurídica de todos os seres, ante ao Novo Constitucionalismo LatinoAmericano. Ao conceber a Natureza como sujeito de direito em uma compreensão pautada nas epistemologias do Sul, emerge o aparato jurídico plural e descolonial. Como consequência mostra-se possível buscar uma nova forma de relação com a Natureza/Haluhalunekisu/Pachamama. A cosmologia Nambiquara, Haluhalunekisu, assim como o Sumak Kawsay e a Suma Qamaña, permite pensar em uma perspectiva 
epistemológica de relação de respeito e integralidade entre seres. Assim, torna-se possível alcançar um novo patamar jurídico-social pautado no paradigma do Buen Vivir. Portanto, esse giro descolonial, quando refletido nos anseios das lutas sociais, convoca o constitucionalismo latino-americano a transformar e reaproxima-se da realidade latino-americana. Isso se torna possível por meio das epistemologias do Sul.

\section{Conclusão}

A partir do estudo epistemológico do constitucionalismo, é possível conhecer as origens histórico-sociais do direito, demonstrando as razões pelas quais encontramo-nos nesse estado de coisas. Do mesmo modo, trata-se de saber que na origem do que hoje entendemos por direito encontra-se uma ideologia que legitima determinadas práticas e distribuições de poder. A história do constitucionalismo demonstra uma preocupação em demasia para com a forma do Direito, em detrimento do conteúdo em si. Enquanto teóricos debruçam-se acerca da distinção entre princípios e regras, não veem o contexto abissal (SANTOS, 2000) em que estas se inserem. Isso porque as razões da crise do positivismo são similares as do póspositivismo, pois ambos permitem barbáries em nome da lei, por serem incapazes de compatibilizar o Direito positivado à realidade social.

Diante desse cenário, questiona-se: Seria o constitucionalismo um reflexo de ideais nacionais ou uma ordem de influência global (mascarada por um Estado Providência ou Estado de Bem-Estar Social), de caráter econômico-cultural (colonialismo e imperialismo), advinda do Ocidente? A constituição é capaz de se defender das influências (desestabilizadoras e aquém da identidade e realidade social nacional) advindas da epistemologia Ocidental? Daí a grande contradição entre democracia e constituição, pois não possuem a mesma identidade (América do Sul versus importação de fórmulas "neutras", "universais", ocidentais). Enquanto a América do Sul ocultar sua identidade, deixar-se dominar e colonizar pelos ideais e pelos interesses do Norte, não será possível a alteridade, a pluralidade de visões de mundo e a interculturalidade.

As constituições da Bolívia e do Equador são uma verdadeira tentativa de responder a essas questões e solucionar o dilema jurídico-social da modernidade: a herança colonial e imperial. Ainda que a América Latina utilize de um instrumento de origem Ocidental para descolonização, a constituição, é possível proporcionar rupturas paradigmáticas. Isso porque o

CONPEDI LAW REVIEW | QUITO - EQUADOR | v. 4 | n. 2 | p. 350 - 371 | JUL - DEZ | 2018 
Novo Constitucionalismo Latino-Americano, no qual se inserem essas constituições, não advém das elites políticas e de dogmas contidos em doutrinas de professores de direito. Ao contrário, são modelos originados das lutas sociais de povos subalternizados e com projetos que refletem epistemologias das camadas sociais oprimidas, vulneráveis, marginalizadas, invisibilizadas. Portanto, o constitucionalismo pode ser transformador do status quo, desde que os povos se organizem politicamente para que o seja. A constituição por si e entregue aos juízes e às autoridades estatais não possuem tal potencial. A mobilização jurídica só será emancipatória se estiver à par da realidade social. Para tanto, é necessário que o sistema normativo também o esteja. Isso é possível por meio de uma mobilização político-social pautada na descolonização do poder, do ser, do saber e do viver (QUIJANO, 2005).

O Novo Constitucionalismo Latino Americano, por pautar-se na descolonialidade, revela o homem latino-americano oculto, oprimido, colonizado e dependente do sistema em que vive. Permite, pela primeira vez à nível epistemológico-constitucional, que se pense o mundo a partir de sua própria localidade. Portanto, para contrapor ao sistema colonial imposto, a cosmovisão indígena mostra-se um eficaz instrumento para se desenvolver uma cultura jurídica latino-americana própria, aquém do etnocentrismo.

Esse caminho deve ser construído assumindo nossa história, aquela que não foi e evita ser contada. Isso implica, também, em assumir nossa realidade e pluriculturalidade. Trata-se de pensar uma teoria crítica desde el Sul e de viés periférico, que reflita anseios e identidades subalternizadas, das minorias, dos indígenas, dos afrodescendentes, dos sujeitos que mais sofrem com a colonialidade. É por meio desses anseios e visões de mundo que se pode concretizar um novo, pautado, por exemplo, no paradigma do Sumak kawsay, Suma Qamaña e Haluhalunekisu que orientam ao Buen Vivir, pois "[...] é preciso imaginar muito para 'viver' um espaço novo.” (BACHELARD, 1978, p. 331).

\section{Referências Bibliográficas}

ACOSTA, A. O bem viver: uma oportunidade para imaginar outros mundos. Tradução de Tadeu Breda. São Paulo: Autonomia Literária. Elefante: 2016.

ÁVILA SANTAMARIA, Ramiro; GRIJALVA JIMENEZ, Augustin; y MARTINEZ DALMAU, Rubén (Ed.). Desafíos constitucionales: la Constitución ecuatoriana de 2008 en perspectiva. Quito: Ministerio de Justicia y Derechos Humanos -Tribunal Constitucional del Ecuador, 2008. 
BACHELARD, Gaston. A poética do espaço. Tradução Antonio da Costa Leal e Lídia do Valle Santos Leal. São Paulo: Abril Cultural, 1978, p. 331. (Os Pensadores).

BITTAR, Eduardo C. B. Metodologia da pesquisa jurídica: teoria e prática da monografia para os cursos de direito. 11. ed. São Paulo: Saraiva, 2013.

BOLZAN DE MORAIS, Jose Luis; STRECK, Lenio Luiz. Ciência política e teoria do Estado. 8. ed. Porto Alegre: Livraria do Advogado, 2014.

BRANDÃO, Pedro. O novo constitucionalismo pluralista latino-americano. Rio de Janeiro: Lumes Juris, 2015.

CARELLI, Vicente; SEVERIANO, Milton. Mão branca contra o povo cinza. Vamos matar esse índio? São Paulo: Brasil Debates, 1980. Centro de Trabalho Indigenista.

COSTA, Anna Maria R. F. M. da. O homem algodão: uma etno-história Nambiquara. Cuiabá: Carlini \& Caniato Editoral : EdUFMT, 2009.

Senhores da memória: uma história do Nambiquara do cerrado. Cuiabá: UNICEN Publicações, 2002. (Tibanaré, 3).

DESCOLA, Philippe. As lanças do crepúsculo: relações jivaro na Alta Amazônia. Tradução Dorothée de Bruchard. São Paulo: Cosac Naify, 2006.

DUSSEL, Enrique. Filosofia da libertação na América latina. Tradução Luiz João Gaio. 2. ed. São Paulo: Loyola, UNIMEP, 1977.

FERRAJOLI, Luigi. A democracia através dos direitos: o constitucionalismo garantista como modelo teórico e como projeto político. Trad. de Alexandre Araujo de Souza e outros. São Paulo: Editora Revista dos Tribunais, 2015.

FLORES, Joaquin H. A (re)invenção dos direitos humanos. Tradução Carlos R. D. Garcia; Antonio H. G. Suxberger; Jefferson A. Dias. Florianópolis: Fundação Boiteux, 2009.

FREIRE, Paulo; FAUNDEZ, Antonio. Por uma pedagogia da pergunta. Rio de Janeiro: Paz e Terra, 1985.

LLASAG FERNÁNDEZ, Raúl. Constitucionalismo plurinacional e intercultural de transição: Equador e Bolívia. In.: Meritum. Belo Horizonte - v. 9 - n. 1 - jan./jun. 2014. p. 265-294.

MARTINEZ DALMAU, Rubén; LEONEL JÚNIOR, Gladstone. O novo constitucionalismo latino-americano e as possibilidades da constituinte no Brasil. In: RIBAS, Luiz Otávio. (Org.). Constituinte Exclusiva: um outro sistema político é possível. São Paulo: Expressão Popular, 2014, v. 1. p. 27-36.

MIGNOLO, Walter. La idea de América Latina (la derecha, la izquierda y la opcion decolonial). Crítica y Emancipación, (2): 251-276, primer semestre, 2009. 
MILLER, Joana. As coisas: os enfeites corporais e a noção de pessoa entre os Mamaindê (Nambiquara). Tese (Doutorado em Antropologia Sociais) - Programa de Pós-graduação em Antropologia Social, Universidade Federal do Rio de Janeiro, Rio de Janeiro, 2007.

OBERG, Kalervo. The Nambicuara. In.: Indian tribes of northern Mato Grosso, Brazil. Washington, n. 15, p. 82-105, 1953. Smithsonian Institution. Institute of Social Anthropology.

PEREIRA, Adalberto Holanda. Os espíritos maus dos Nambikuára. In.: PEREIRA, Adalberto Holanda. Pesquisas. São Leopoldo: Instituto Anchietano de Pesquisas, 1973. (Antropologia, 25).

PEREIRA, Caio Mário da Silva. Instituições de direito civil. Volume I. 19a ed. Rio de Janeiro: Forense, 1999.

PRICE, Paul David. Nambiquara society. Thesis (For the degree of Doctor of Philosophy). Department of Anthropology, Faculty of the Division of the Social Sciences. Chicago: Illinois, 1972.

. Before the bulldozer: the nambiquara indians \& the World Bank. Washington: Seven Locks Press, 1989.

QUIJANO, Aníbal. Colonialidade do poder, eurocentrismo e América Latina. In: LANDER, Edgardo (Org.). A colonialidade do saber: eurocentrismo e ciências sociais. Perspectivas latino-americanas. Clacso, set. 2005, p. 227-278 (Colección Sur Sur). Disponível em: http://bibliotecavirtual.clacso.org.ar/libros/lander/pt/Quijano.rtf Acesso em: 25.03.2018.

SANTOS, Boaventura de Sousa. A crítica da razão indolente: contra o desperdício da experiência. São Paulo: Cortez, 2000.

2010.

A gramática do tempo: para uma nova cultura política. $3^{\text {a }}$ ed. São Paulo: Cortez,

SOUSA, Adriano Corrêa de. A emancipação como objetivo central do novo constitucionalismo latino-americano: os caminhos para um constitucionalismo da libertação. In: O pensamento pós e descolonial no novo constitucionalismo latino-americano. VAL, Eduardo Manuel; BELLO, Enzo (Orgs.). Caxias do Sul: Educs, 2014, p. 65-86. Disponível em: https://www.ucs.br/site/midia/arquivos/pensamento_pos.pdf. Acesso em: 16.05.2018.

VIVEIROS DE CASTRO, Eduardo. A inconstância da alma selvagem e outros ensaios de antropologia. São Paulo: Cosac Naify, 2002.

WALSH, Catherine. Interculturalidad, plurinacionalidad y decolonialidad: las insurgências político-epistémicas de refundar el Estado. In: Tabula rasa. $\mathrm{n}^{\circ}$ 9, 2008, p. 131-152. Disponível em: http://www.revistatabularasa.org/numero-9/08walsh.pdf. Acesso em: 16.03.2018.

YRIGOYEN FAJARDO, Raquel Zonia. El horizonte del constitucionalismo pluralista: del multiculturalismo a la descolonización. In.: GARAVITO, César Roberto (Comp.). El

CONPEDI LAW REVIEW | QUITO - EQUADOR | v. 4 | n. 2 | p. 350 - 371 | JUL - DEZ | 2018 
derecho en América Latina: un mapa para el pensamiento jurídico del siglo XXI. Buenos Aires: Siglo Veintiuno, 2011, p. 139-184.

ZAFFARONI, Eugênio Raúl. La natureza como persona: pachamama y gaia. In: VARGAS, Chivi; MOISES, Idón (Coords.) Bolivia - nueva constitucion política del Estado: Conceptos elementales para sudesarrollo normativo, La Paz, 2010.

2012.

. La pachamama y el humano. Buenos Aires: Ediciones Madres de Plaza de Mayo, 